\title{
HISTORIAS MÍNIMAS: LAS CARTAS EN LA GUERRA CIVIL ESPAÑOLA
}

\author{
Javier Cervera Gil \\ Universidad Francisco de Vitoria \\ xavicg@yahoo.es
}

Recibido: 14/07/2016 - Aceptado: 19/10/2016

Cómo citar este artículo/Citation:

Javier CERVERA GIL (2017), "Historias mínimas: las cartas en la Guerra Civil española”, Hispania Nova, 15, págs. 125 a 146,

DOI: https://doi.org/10.20318/hn.2017.3483
Copyright: (c) HISPANIA NOVA es una revista debidamente registrada, con ISSN 1138-7319 y Depósito Legal M 9472-1998. Los textos publicados en esta revista están -si no se indica lo contrario- bajo una licencia Reconocimiento-Sin obras derivadas 3.0 España de Creative Commons. Puede copiarlos, distribuirlos y comunicarlos públicamente siempre que cite su autor y la revista y la institución que los publica y no haga con ellos obras derivadas. La licencia completa se puede consultar en: http://creativecommons.org/licenses/by-nd/3.0/es/deed.es
Resumen: Las cartas cuentan las historias mínimas, pero esenciales, de la Guerra Civil Española. Ellas presentan la visión más humana y más cercana a la verdadera realidad de los españoles que vivieron aquella Guerra. En este trabajo analizamos el funcionamiento del correo y sus dificultades, el material utilizado para escribir cartas, el lenguaje utilizado, el nivel cultural de los españoles que revelan los textos escritos y los temas más presentes en las cartas de la Guerra Civil. Un paisaje muy completo de la realidad cotidiana de los españoles que participaron en la Guerra de España.

Palabras clave: Guerra Civil Española, Correo, Vida diaria, Propaganda, Historia anónima
Abstract: The letters have minimum but essential stories of the Spanish Civil War. They have the most humane and closer to the true reality of the Spaniards who lived through that war and his rearguard. This paper analyzes the operation of the mail and its difficulties, the material used to write letters, the language express the cultural level of Spanish. The analisys of letters reveal the topics that interest the spanish. A comprehensive landscape of the everyday reality of the Spanish who participated in the War of Spain.

Keywords: Spanish Civil War, Mail, Daily life, Propaganda, Anonymous history 


\section{HISTORIAS MÍNIMAS: LAS CARTAS EN LA GUERRA CIVIL ESPAÑOLA}

\section{CONSIDERACIONES PRELIMINARES ${ }^{1}$.}

Las bases de la socialización del servicio de correos se asentaron gracias al Estado liberal, a partir de los años treinta del siglo XIX. Y cuando terminó el reinado de Isabel II ya estaba garantizado el servicio de correos al último rincón del país, en relación directa con la eclosión del ferrocarril en España. Desde la Restauración se acentuaría esa tendencia en el crecimiento de la circulación postal en España. De 71 millones de cartas que circularon en 1868, pasamos a los 277 millones en vísperas de la Guerra Civil, casi cuatro veces más. Eso sí, en tiempos de la Segunda República el número de cartas por cápita en España era de 11, frente a las 42 ' 5 de Alemania, las casi 37 de Francia, las 24 de Bélgica o las 16 de Italia. Esto nos aporta una idea del ritmo de socialización del correo en España en comparación con Europa Occidental. A esta realidad se unía el correo aéreo².

En suma, cuando se inició la Guerra Civil, los españoles escribían cartas, el correo era ya un sistema consolidado y eficaz de comunicación en España y, sobre todo, era un elemento más en la vida ordinaria de las gentes.

Que ello fuera así, supone una gran ventaja para los historiadores. La normalización y regular eficacia de un sistema de correo aporta una valiosa fuente documental para que, ocho décadas después, conozcamos jugosos detalles de la vida cotidiana de aquella terrible guerra civil.

En el marco de la tragedia que asoló España de 1936 a 1939 hallamos los testimonios personales e intransferibles de quienes, desde el anonimato, hicieron aquella guerra: son las historias mínimas. Estas las encontramos en cartas íntimas de hijos a padres, entre novios, entre hermanos, entre madrina de guerra y ahijado, entre amigos, entre camaradas de partido o sindicato, entre familiares lejano.

Los académicos han explorado muchos supuestamente grandes hombres y colectividades (generales, políticos, líderes, autoridades o cargos, partidos, sindicatos, clases, géneros, y los ejércitos

\footnotetext{
${ }^{1}$ Este artículo forma parte del proyecto de investigación con referencia HAR2015-70256-P, financiado por el Ministerio de Economía y Competitividad de España, en el marco del Plan Estatal de Investigación Científica y Técnica y de Innovación 2013-2016.

2 Ángel BAHAMONDE MAGRO (dir.); Gaspar MARTínEZ LORENTE y Luis Enrique OTERO CARVAJAL, Las comunicaciones en la construcción del Estado contemporáneo en España, 1700-1936. Madrid; Ministerio de Obras Públicas, Transporte y Medio Ambiente; 1993.
} 
en batalla), pero, también, encontramos también exploraciones históricas sociales "desde abajo", y especialmente desde el análisis de testimonios epistolares ${ }^{3}$.

Y en las cartas encontramos mucha realidad de la Guerra. Las cartas nos trasladan tanto las vivencias de las trincheras como las de la retaguardia. Son relatos que gozan de la frescura de haber sido aportados desde el mismo momento en que sucedieron los hechos. Las cartas poseen el don de la inmediatez: aquéllos que hicieron o sufrieron la guerra nos la cuentan mientras la vivían, sin los embellecimientos y máscaras que se añaden a los recuerdos, que son matizados o modificados por el paso del tiempo.

\section{UN CORREO QUE TIENE QUE FUNCIONAR.}

El fracaso de la sublevación militar transformaría, en unas semanas, la situación de España en una guerra. Inopinadamente, moverse por España se tornó, no ya difícil, sino peligroso y aun imposible en muchos casos. Y surgieron familias separadas, amigos distanciados geográficamente, españoles, que se hallaban de veraneo, lejos de su residencia habitual y, como no, primero jóvenes, más adelante, más maduros, que fueron movilizados o que se presentaron voluntarios para la lucha y que debieron alejarse del hogar.

Durante los primeros meses de la guerra, la tranquilidad fue algo relativamente raro. Unido a ello, el número de voluntarios en ambas zonas fue más o menos similar, en relación con la población. Pero, en esa primera etapa, el entusiasmo decreció conforme estos combatientes experimentaron la crudeza y el riesgo del frente. $Y$ cuando las fuerzas de Franco fueron fácilmente avanzando hacia la

\footnotetext{
${ }^{3}$ Referido a la Guerra Civil tenemos trabajos de la profesora Verónica Sierra Blas o los coordinados por Antonio Castillo Gómez, pero, como aparecerán citados en puntos específicos de este trabajo, citemos ahora otras aportaciones. Michael SEIDMAN, "Quiet fronts in the Spanish Civil War" en The Historian, vol. 61 (junio de 1999), pp. 821 a 842; o en James MATTHEWS, Voces de la trinchera: cartas de combatientes republicanos en la Guerra Civil española. Madrid, Alianza Editorial, 2015. Y abundan los recopilatorios de testimonios como en Antonio DíEZ, Brigadas Internacionales: cartas desde España: brigadistas del Gran Manchester en el Batallón Británico de la XV Brigada (Badajoz, Manuel Moya Editores Extremeños; 2005); el de Nacho BLANES, Adrián SÁNCHEZ CASTILLO y Paul QUINN, Las cartas del Batallón Británico: las Brigadas Internacionales en la Guerra Civil española (Madrid; Los libros de la Catarata; 2014), el de Peter N. CARROLL y OTTANELLI, Letters from the Spanish Civil War: A.U.S. Volunteer writes home (Kent; The Kent State University Press, 2013); sobre mujeres, Gerd-Rainer HORN (ed.), Letters from Barcelona: an American woman in revolution and Civil War (New York; Palgrave Macmillan, 2009), o en el seno del Grupo de Investigación de la Batalla del Ebro de la Universidad Rovira i Virgili; Lluc MARGALEF BOQUERA, Diari de guerra d'en Magí Domènech i Martí. (Valls, Cossetània Editions; 2014). Y, aparte de las referencias estadounidenses citadas, también se hacen este tipo de análisis fuera de España y referidos a las guerras mundiales. Por ejemplo, en Alemania tenemos a Eberhard BETHGE, Widerstand und Ergebung: Briefe und Aufzeichnungen aus der Haft (Múnich; Kaiser, 1985), en Francia a Guy KRIVOPISSKO, Vivir a muerte: últimas cartas de fusilados, Francia 1941-1944 (Barcelona, Barril \& Barral, 2009) o en Italia a Antonio GIBELLI, Antonio, L'officina della guerra: la Grande Guerra e le transformazioni del mondo mentale (Turín, Bollati Boringhieri, 2007 -primera 1991-); o Fabio CAFFARENA, Lettere dalla Grande Guerra. Scritture del quotidiano, monumento della memoria, fonti per la storia. II caso italiano (Milán; Unicopli; 2005).
} 
capital en agosto, cientos de madrileños se comprometieron a luchar, pero sólo una minoría cumplió con su compromiso ${ }^{4}$.

Un número apreciable de milicianos del Ejército Popular, en los frentes en torno a Madrid, pronto perdieron interés por el combate y olvidaron su entusiasmo inicial. En Aragón, el frente se estabilizó rápidamente, es decir, que se convirtió en tranquilo, y los combatientes arriesgaron menos su vida ${ }^{5}$.

En el lado franquista, también las milicias locales resultaron menos entusiastas y tuvieron que ser complementadas por requetés navarros más comprometidos, en unidades militares carlistas.

Sea como fuere, para todos los que fueron al frente y muchos que quedaron en la retaguardia, el correo se convirtió durante mucho tiempo en el único modo de relación con los seres queridos.

Pero, además, estamos ante un conflicto que generó que, de un Estado, con una administración y un sistema postal, surgieran, en cuestión de meses, dos. Hubo una frontera que separaba España. Pero, a pesar de esa división, el correo se convertiría en el instrumento fundamental para poder saber de la vida de los familiares, amigos, novia/novio, compañeros de trabajo... Mediante diversos medios, sí hubo comunicaciones postales entre las dos Españas.

Como muchas relaciones dejaron de ser personales para ser postales, el cartero se convirtió en un personaje vital en las relaciones humanas de la Guerra Civil. Porque las cartas, muchas veces, mantuvieron la moral, el estado de ánimo de quien lo estaba pasando mal, a veces muy mal, en la trinchera o en la retaguardia. Y lograr mantener el funcionamiento del sistema de correo fue complicado, especialmente cuando las cartas se dirigían a los combatientes, en unidades que no dejaban de desplazarse de un lugar a otro. Así, Miguel, soldado republicano, se lamenta de que "hace 15 días que no he tenido carta tuya y tú no te puedes figurar lo 'despaciente' (sic) que yo estoy al estar tanto tiempo sin saber noticias tuyas. Pero vamos no es culpa tuya, ni culpa mía, es culpa de cambiar yo de frente, porque al sitio que yo estaba (...) las cartas han llegado al tiempo. En esta carta te digo la dirección que yo tengo aquí, que estoy yo" ${ }^{\prime 6}$.

O Pedro, en las trincheras franquistas, el 16 de diciembre, optó por felicitar a su amigo Manolo la Navidad y decidió unirla a la del Año Nuevo (1939)... "iEconómico que es uno! Aunque temo que ésta tarde bastante en llegarte, pues nuestro correo lleva varios días detenido y no me extrañaría que continuara así más tiempo"'?.

En suma, hubo retrasos y dificultades, pero no sería justo decir que el correo no funcionó porque, en general, las cartas sí alcanzaron su objetivo (otra cosa fueron los paquetes, cuyo contenido, a veces apetecible o tentador, hacía que se quedaran por el camino y no por responsabilidad muchas veces del cartero). La mayoría llegaron a sus destinatarios quienes en muchos casos han sido quienes

\footnotetext{
${ }^{4}$ Ramón SALAS LARRAZÁBAL. Historia del Ejército Popular de la República. Madrid, Editora Nacional, 1973. y SEIDMAN, Michael. Op. Cit.

${ }^{5}$ SEIDMAN, Michael. "Quiet fronts...” op. cit.

${ }^{6}$ Carta de Miguel Bedos a su novia Josefina Bes (7/07/1937): Archivo particular de Francisco Cabrera Castillo.

${ }^{7}$ Carta de Pedro María Ortiz a Manuel Valenzuela Peralta (16/12/1938). Fondos Incorporados; caja 1; Carpeta "L414.196: Correspondencia a Manuel Valenzuela Peralta". Centro Documental de la Memoria Histórica de Salamanca (en adelante, CDMH-SALAMANCA).
} 
nos las han permitido consultar. En otras ocasiones, las hemos hallado en el Centro Documental de la Memoria Histórica de Salamanca. ${ }^{8} \mathrm{Y}$ en la gran cantidad de correspondencia que hemos analizado brillan por su ausencia referencias a pérdidas de cartas. Por ello, pensamos que aunque habría casos no debieron ser en un número significativo ${ }^{9}$.

También, como consecuencia de la marcha de las operaciones y el avance de la guerra, surge otra circunstancia que prestigia la profesionalidad de los carteros. Muchos lugares pasaron de unas manos administrativas a otras, es decir, dejaron de ser atendidos por el sistema de correo y carteros republicanos, para serlo por los franquistas. La situación provocó desajustes y demoras lógicas en el sistema, pero también situaciones paradójicas.

Así, encontramos cartas con un matasellos republicano de fecha posterior al día en que tal pueblo o ciudad cayó en manos de los franquistas. El motivo de esta circunstancia fue que los profesionales de Correos se marchaban en huída del pueblo donde trabajaban para escapar de la ocupación de los franquistas y lo hacían cargando con la saca de la correspondencia y los matasellos. Y cuando llegaban a un lugar tranquilo, procedían a desarrollar su trabajo: aplicaban el "matasello" que llevaba fecha del día y referencia al lugar de procedencia que ya no era republicano. A partir de ahí comenzaba la distribución de la carta, con un matasellos "imposible" teóricamente ${ }^{10}$.

Y esa progresiva ocupación de España nos proporciona otras curiosidades en la correspondencia. Los franquistas pusieron en servicio de nuevo el correo en la estafeta del lugar y, lógicamente, emplearon el material postal que allí se encontraba: durante un tiempo "matasellaban" utilizando "iconografía" republicana y se distribuyeron sellos en los que seguía figurando "República Española". Fue inevitable.

Pero hasta aquí nos hemos referido al correo "ordinario" durante la Guerra Civil (si es que se puede de hablar de "ordinario" en aquellas circunstancias). La partición de España separó familiares o grupos de amigos de forma tajante, pero se arbitró algún modo de comunicar postalmente a personas separadas en ambas zonas.

Es muy conocida la labor que realizó la Cruz Roja. A través de esta organización internacional se tramitaron tarjetas con mensajes muy escuetos porque se incluían en formularios ya muy estructurados. El remitente escribía sus datos y contaba con unas pocas líneas (cinco o seis) para el texto. Es más, en algunos casos hemos encontrado la indicación: "No más de quince palabras y asuntos

\footnotetext{
${ }^{8}$ Este gran centro conserva colecciones de cartas en la sección "Archivos Privados" que alberga, además de otras cosas, en torno a medio centenar de colecciones de las cartas casi todas de tiempos de la Guerra Civil. Como se puede comprobar en su WEB, han sido adquiridas, ninguna antes del año 2000, por donación o por compra, en este caso, ninguna por incautación franquista, como sí ocurre otros fondos de este archivo. Es más se catalogan como "fondos incorporados".

${ }^{9}$ Francisco ARACIL. La Guerra Civil en la Historia Postal. Madrid; Biblioteca de Historia Postal; 1996 (pp. 90 y 91): afirma que la mayor parte de las cartas llegaban a su destino.

${ }^{10}$ Hemos podido comprobar ejemplos de esta realidad en la colección postal particular de don Ángel Bahamonde Magro. Además también constata esta realidad Francisco ARACIL, La Guerra Civil... op. cit. (p. 80).
} 
familiares". El remitente acudía a la oficina del Comité Local de la Cruz Roja del lugar y rellenaba uno de esos formularios poniendo las señas del lugar de envío y el breve escrito. ${ }^{11}$

En menos ocasiones, se podía escribir algo más en una cuartilla, algo que sí que era más bien una carta, pero para ello se empleaba un sobre especial, proporcionado también en la oficina de la Cruz Roja, y en el que constaba, aparte del sello de la franquicia otro que revelaba que había pasado la censura: "Como encargado del registro certifico: que este pliego contiene solamente correspondencia oficial."... que muchas veces era más bien privada

Fueran estos sobres o los anteriores impresos más sucintos, en ambos casos se enviaban a Ginebra, desde donde se remitían al lugar de España que había sido indicado por el remitente ${ }^{12}$.

Además, hubo españoles que idearon otro sistema: introducían un sobre con una carta en otro sobre y esto lo enviaban a un conocido que residía fuera de España. Este, cuando lo recibía, enviaba la primera, desde el extranjero a la otra zona. Obviamente, había que conocer a alguien que residiera fuera de España, cosa no al alcance de muchos españoles. Este fue el caso de Alberto Nadal, en las filas franquistas en los alrededores de Madrid, escribió a su novia Elvira ubicada a sólo unos pocos kilómetros... pero en el interior de la capital ${ }^{13}$. Además, el censor que tendría mucho trabajo -como era lo habitual- es lógico que si alguna podía dejar de revisar estaría entre aquellas que iban destinadas al extranjero, que podría pensarse, por ello, que era una carta poco peligrosa.

Y en 1937 aparece otra realidad: el exilio de miles de vascos que, cuando en el verano de 1937 Guipúzcoa y Vizcaya fueron ocupadas por los franquistas, primero por Irún y después en barcos desde puertos del Cantábrico, huyeron de España. Por eso, el gobierno vasco arbitró la manera de intentar comunicar a miembros separados de las familias mediante unas cartas-formulario en las que, tras figurar los datos personales, había unas líneas para colocar un mensaje. Desde el mismo vapor "Habana", camino ya de Francia, Florentina quiso saber de su hijo Martín que estaba en Santander en el Batallón de las Milicias Unificadas de Larrañaga, 4a Compañía, 3a Sección, y por si ese mensaje le llegara, escribió: "Querido hijo, me alegraré que al recibo de estas cortas letras te alles (sic) bien. Nosotras bien. No te escribo más sólo para saber tus noticias que estoy deseando por recibirlas. Tu madre que mucho te quiere y tú recibes un fuerte abrazo de tu madre y hermanos"14. No cabía más en el espacio concedido; firmó y después escribió las señas del lugar donde iba a residir Florentina, concretamente en Saint-Etienne (Loire).

Otra realidad similar fue la de los niños que fueron evacuados fuera de España, para alejarlos del riesgo y la penuria hacia Francia, Bélgica, Reino Unido, la URSS, en Europa, o México al otro lado del Atlántico. Pero los padres y el resto de familiares estaban en España y para mantener el contacto aparecieron las Delegaciones de Asistencia Social que en distintos lugares de la España republicana

\footnotetext{
${ }^{11}$ Una fotografía de estas tarjetas de la Cruz Roja se puede ver en Francisco ARACIL, La Guerra Civil... op. cit. (p. 77).

${ }^{12}$ Testimonio documental del funcionamiento de este operativo de la Cruz Roja lo hemos hallado en el Archivo particular de la familia de Carmen Lomas Pastor.

${ }^{13}$ Carta de Alberto Nadal Baquedano (s. f, pero de 1937) a su novia Elvira Gómez-Martinho. Archivo particular de Paloma Nadal Gómez-Martinho.

${ }^{14}$ Carta de Florentina Silva Aramendi a su hijo Martín (26/06/1937). Carpeta "Cartas", GE, K. 00024, C. 17. Archivo Histórico del Nacionalismo Vasco-Fundación Sabino Arana.
} 
(Asturias, Valencia, País Vasco...) contaron con funcionarios de correos para ese fin. Además, también a ellos acudieron los padres y familiares que depositaban en ellos la esperanza de mantener el contacto con sus niños. Las dificultades eran enormes, pero el esfuerzo y la dedicación de estas delegaciones y sus funcionarios para alcanzar el éxito de comunicar al niño con sus familiares eran mayores.

Verónica Sierra nos presenta gran cantidad de estas cartas en la que los niños contaban el viaje desde España a su destino, cómo estaban allí o pedían a "los camaradas" de la delegación de asistencia ayuda para localizar a sus padres. Cuando los pequeños eran incapaces de escribir se ayudaban de manos más expertas porque querían, primeramente, no perder contacto con sus padres bajo ningún concepto, y, después, informarles de su nueva vida. Eso sí, en estas cartas infantiles tampoco faltaban consignas ideológicas y mensajes propagandísticos que revelan el control y la influencia externa de algún adulto ${ }^{15}$.

Por otro lado, y dentro de la España republicana, a partir de abril de 1938, la comunicación postal se encontró con una nueva dificultad: la zona republicana quedó partida en dos, al alcanzar los franquistas el Mediterráneo por Vinaroz. Los amigos o familiares en el centro peninsular no iban a poder saber, de momento, la suerte que corrían los que quedaron en Cataluña y al revés. En el archivo postal cenetista encontramos cartas de combatientes angustiados por esta interrupción del servicio de correo entre ambas zonas ${ }^{16}$.

\section{UNA TRABA AL FUNCIONAMIENTO DEL CORREO: LA CENSURA.}

Otra faceta del funcionamiento de la correspondencia bélica es la censura, un elemento clásico al comentar las cartas de cualquier guerra.

En el bando franquista, con un estado de guerra, cabría pensar que la censura militar, a la que se sumó otro control de carácter moral y/o religioso, sería rigurosa y eficaz. Pedro escribió: “... donde ahora estamos, de cuyo nombre no quiero acordarme y aunque quisiera, no me lo dejaría poner el Pater, que es quien ejerce la censura." Por tanto, ya revela que el capellán, además de su atención espiritual, se encargó de la censura. Debió de ser mucho trabajo porque delegó en un oficial con formación universitaria y de cuyo criterio, acorde a los valores de esa España, se fiaba. Es el caso del citado alférez, Pedro, que se quejaba de su enorme cantidad de trabajo "...además estaba muy cansado de la censura de las cartas. (...) Por término medio venían a resultar unas 500 diarias. Y casi todo el trabajo lo tenía yo que hacer porque aunque tenía un compañero, este eludía el trabajo cuando podía"17.

Pero, lo cierto es que, la censura franquista tampoco fue tan eficaz. En las primeras semanas de la Guerra la realizaron autoridades militares, falangistas o autoridades civiles, antes de que lo hicieran capellanes y antes de que se dictaran las primeras normas para ello.

Esto llegó el 2 de septiembre de 1936 cuando se excluyó de la censura a los vocales de la Junta de Defensa Nacional, al resto, por tanto, no. La excepción se ampliaría al mando supremo de cada

\footnotetext{
${ }^{15}$ Verónica SIERRA BLAS. Palabras huérfanas. Los niños y la Guerra Civil. Madrid; TAURUS; 2009 (pp. 145 y 146, y 276 a 280).

${ }^{16}$ Archivo de la Fundación de Estudios Libertarios Anselmo Lorenzo (CNT).

${ }^{17}$ Varias cartas de Pedro María Ortiz a Manuel Valenzuela Peralta (diciembre de 1938). Fondos Incorporados; caja 1; Carpeta "L-414.196: Correspondencia a Manuel Valenzuela Peralta.". CDMH-SALAMANCA.
} 
división y el 28 de diciembre a la correspondencia de organismos gubernamentales. Las marcas en los sobres eran "Censurado", "Censura Militar" o "Abierta por la censura", y al poco se añadiría el municipio de procedencia. Así, el correo actuaba de refuerzo moral cuando aparecían localidades que al principio estaban en manos republicanas.

Pero en 1937 encontramos dos normas, el 28 de mayo y el 26 de noviembre, cuyo objetivo era atajar comportamientos que burlaban la censura en correspondencia dirigida al extranjero, luego había fallos. Es más, estos persistieron porque el 17 de febrero de 1938 otra circular, además de reiterar las normas, reconocía que había quienes se aprovechaban de la franquicia arancelaria de los envíos militares para burlar el pago de las tasas aduaneras. Incluso unos días después, otra circular, de nuevo, denunció que continuaban las entregas de correspondencia sin las señales de censura debidas.

Y la exitosa evolución de la guerra para los franquistas no ayudó a corregir estos fallos y se detectaba cierta relajación. A comienzos de 1939, la Jefatura Principal de Correos denunció que había correspondencia que no se censuraba, por lo que, en fecha ya tan tardía como el 6 de marzo de 1939, se insistió en la obligatoriedad de la censura militar antes de entregar las cartas. También, esta disposición reveló que terminaría pronto la guerra (tres semanas después), pero ni mucho menos terminó la censura postal... Hasta 1945 no se garantizó la inviolabilidad de la correspondencia en España. ${ }^{18}$

Y tampoco fue más rigurosa la censura en la España leal al Frente Popular. Hasta la primavera de 1937, la República atravesó un "periodo de caótica situación a niveles gubernamentales y administrativos" que, lógicamente, también afectó al ámbito del correo ${ }^{19}$. Aún así, intentó regular la censura antes que en el lado rebelde: Un decreto del 15 de agosto, ordenó al Director General de Correos que organizara un servicio de censura para toda la correspondencia con origen o destino en el extranjero, y esta se efectuaría en Madrid, Barcelona, Valencia e Irún, y en Seo de Urgel para la de Andorra. Pero, como señala Heller ${ }^{20}$, antes de esa norma, ya se censuraba correspondencia en Barcelona, porque asumieron funciones de censura autoridades municipales, comités, organizaciones políticas y/o sindicales... aunque no hubiera ninguna disposición legal que las habilitara para ello. El Consejo de Asturias y León, por ejemplo, aprobaba unas instrucciones muy detalladas para la censura el 6 de marzo de 1937.

Y cuando el gobierno republicano restableció una estructura del estado más sólida, tampoco fue prolijo en disposiciones para regular la censura. El 15 de octubre de 1937 se prohibía la circulación de tarjetas postales ilustradas con vistas parciales o totales de poblaciones o cualquier paisaje "del territorio leal". ${ }^{21} \mathrm{Y}$ en 1938 únicamente hubo tres normas menores más. Una (22 de agosto) que

\footnotetext{
${ }^{18}$ Ernst L. HELLER. Marcas utilizadas por la censura postal nacional de 1936 a 1945. Madrid; Lidner Filatélica Ibérica, 2000 (pp. 15 a 17).

${ }^{19}$ Ernst L. HELLER, Marcas utilizadas por la censura republicana durante la Guerra Civil Española. Madrid; Lidner Filatélica Ibérica, 1995 (p. 5). Esa situación de desorden y falta de autoridad del gobierno republicano la corroboran muchos estudios. Citemos un clásico, el de Gabriel JACKSON: La República española y la guerra civil (1931-1939); Barcelona; Ediciones Orbis; 1985 (pp. 249 a 262). Y otro recién actualizado: Paul PRESTON; La Guerra Civil Española; Barcelona; Debate; 2016; (pp. 241 a 273).

${ }^{20}$ HELLER, Ernst L. Marcas utilizadas por la censura republicana... op. cit., p. 6.

${ }^{21}$ HELLER, Ernst L. íbidem, p. 37.
} 
centralizó los servicios de censura en una Oficina Central en Barcelona. Y otras dos (ambas, el 26 de noviembre): una privilegiaba el uso de tarjetas para la comunicación familiar o particular porque tendrían preferencia en la oficina de censura, y otra prohibía enviar billetes de banco en las cartas al extranjero.

Esos problemas de eficacia en la censura de la España republicana también guardaron relación con las banderías políticas enfrentadas en el seno de la retaguardia. Así, desde Bilbao, Romualdo, peneuvista, escribió a principios de la guerra que "esos canallas de socialistas, comunistas y CNT no cometan más crímenes con los presos..." o que "hay que tener en cuenta que también los leales bombardean otras poblaciones, con que ninguno debiera hacer tales cosas, sino en los frentes donde está la lucha ahora..."22

Pero más frecuentes fueron los ataques entre anarquistas y comunistas. En cartas de los primeros leemos en 1938 cosas como..."El Comisario de la Comandancia Militar de Figueras (...) pertenece al partido comunista; este individuo a pesar de no tener nombramiento oficial, hace cuanto le viene en gana..." y procedía a describir una serie de corruptelas protagonizadas por este comisario. 0 desde un batallón de la 151 Brigada Naval un confederal escribió que "ya sabes cómo los mandos de esta brigada dejan mucho que desear y más aún si lo miramos desde el punto de vista político, pues hay muchos de ellos fascistas encubiertos..." y se refiere a varios del $\mathrm{PCE}^{23}$.

También los combatientes republicanos comentaban esa ineficacia... José, desde Tarragona, contó a su familia que "ha sido la primera carta que he recibido abierta por la censura de guerra, ya que hasta ahora no se habían tomado la molestia de leer las cosas insustanciales que nos contamos." ${ }^{24}$.

Pero, desde luego, en ambos bandos, los combatientes fueron conscientes de que las cartas no podían incluir referencias a datos, posiciones, informaciones... militarmente relevantes, y esto no aparecía casi nunca.

Eso sí, cuando, a finales de 1938, los soldados republicanos estaban hartos de la vida en las trincheras. Los censores encontraron quejas sobre la comida, la más común de todas las quejas. Algunos lamentaron la reiteración de la dieta (arroz, aceite de oliva y pan para el desayuno, el almuerzo y la cena) que, además, escaseaba, cada vez más. O describían en esas cartas el triste espectáculo de las mujeres y niños descalzos que se encontraban pidiendo regularmente por los restos escasos en torno al Ejército Popular. Y todo ello, a estas alturas de la Guerra, pasaba el examen del censor.

Porque además, entonces, se les acumuló el trabajo y había falta de personal. Debían leer decenas de miles de cartas, y asomó el "pobre espíritu combativo" en los hombres, la mayoría de los cuales estaban en Cataluña y Valencia. Cientos trataron de engañar a los censores introduciendo un

\footnotetext{
${ }^{22}$ Carta de Romualdo Artaza (09 ó 10/1938). GE 26:12. Archivo Histórico del Nacionalismo Vasco-Fundación Sabino Arana.

${ }^{23}$ Carta del Secretario de la Regional de Asturias, León y Palencia de la CNT (13/12/1938). Microfilmes 52; paquete 27, Caja 327, C. Archivo de la Fundación de Estudios Libertarios Anselmo Lorenzo (CNT).

${ }^{24}$ Carta de José Nogué Vallejo a su familia (5/08/1938). Fondos Incorporados; caja 2; Carpeta "Correspondencia del soldado José Nogué Vallejo con su familia durante la Guerra Civil (1936-1939)". CDMH-SALAMANCA.
} 
sobre dentro de sobres, y el desánimo y el convencimiento en una derrota ya próxima conducía a la dejadez del censor en el cumplimiento de su deber. La censura tiraba la toalla ${ }^{25}$.

\section{CON QUÉ Y EN QUÉ SE ESCRIBE: EL MATERIAL DE LAS CARTAS.}

Gran cantidad de testimonios, en las mismas cartas, sobre todo en la España republicana y ya claramente desde primeros de 1938, manifiestan la escasez de papel y de sellos. ${ }^{26}$ En cuanto a los sobres, se recurría a fórmulas de tarjetas prefranqueadas que, por tanto, además, subsanaban la falta de sellos. También es verdad que estas carencias empezaron a manifestarse también en la otra España, pero ya en 1939.

En primer lugar, nos encontramos con papeles de los más variados tipos y cada vez de menor calidad. Y cuando escaseó, encontramos la escritura superpuesta en perpendicular. Es lo que se denomina "escritura en reja" o "escritura cruzada": sobre parte de lo que había escrito antes pero en sentido perpendicular. Aunque cueste, con un poco de esfuerzo se lee perfectamente. Eran los remedios para cuando faltaba papel.

En los años treinta, el envío de postales era ya habitual entre los españoles. En la Guerra, junto a los bellos paisajes o monumentos significativos, se sumó la propaganda. Entre los franquistas, se distribuyeron postales con la imagen de Francisco Franco con porte altivo y, lógicamente, vestido con su uniforme de general. Fue el más habitual, pero también hemos encontrado postales con la fotografía de otros militares destacados del bando franquista tales como Emilio Mola, Solchaga, Yagüe, Queipo de Llano... e incluso eclesiásticos como el Cardenal Gomá. Y en el caso republicano esto también sucedió pero menos: fueron más frecuentes las postales en las que se reproducía (y no he encontrado ejemplos de esto en el bando franquista) carteles de los muchos que se editaron en la España republicana ${ }^{27}$.

En la retaguardia franquista no escaseaban tanto los sellos, pero si sucedía, como se ha mencionado antes, se emplearon sellos republicanos un tiempo. Y, además, en ocasiones, se añadió alguno adicional "pro-beneficencia" con valor de 5 céntimos habitualmente. Pronto empezaron a aparecer cartas con sellos de imágenes acordes a los valores de la nueva España como la efigie de Isabel La Católica. Los que portaban a Franco no aparecieron hasta una vez terminada la guerra. ${ }^{28} \mathrm{Sin}$ embargo, en el frente muchos oficiales franquistas prescindieron de los sellos, y simplemente estampaban el anagrama de la unidad a la que pertenecían y a veces el sobre portaba frases como "servicio de campaña".

\footnotetext{
${ }^{25}$ SEIDMAN, Michael. “Quiet fronts,,," Op. cit.

${ }^{26}$ Referencias a estas carencias las hemos leído en cartas fechadas desde julio de 1937 y, desde luego, en 1938 que se conservan en el Archivo particular de Francisco Cabrera Castillo; en Fondos Incorporados; Caja 2: Carpeta "Correspondencia del soldado José Nogué Vallejo con su familia durante la Guerra Civil (1936-1939)" del CDMHSALAMANCA, o en Microfilm 253; Paquete 91; Carpetas C.2 y C.3. del Archivo de la Fundación Anselmo Lorenzo (CNT)

${ }^{27}$ Jordi CARULLA y Arnau CARULLA. La Guerra Civil en 2000 carteles. República-Guerra Civil-Posguerra. Barcelona; Postermil; 1997 (Vol. 2).

${ }^{28}$ Francisco ARACIL, La Guerra Civil... op. cit. (p. 91)
} 
Donde sí escasearon más los sellos fue en la España republicana. Sólo un año después de iniciada la guerra, le pedía a su novia que... "cuando me escribas si puedes enviarme un sello, envíamelo, porque aquí pasa una cosa, que sellos aquí no hay, y si envías una carta sin sellos se pierde la carta. Así si envías un sello cuando escribes, yo te podré contestar a vuelta de correo"29.

Pero los republicanos sabían que esta escasez no debía impedir que en el frente, y también en la retaguardia, siguiera funcionando el correo. Y los combatientes podían acudir a la "Tarjeta Postal de Campaña", ya pre-franqueada y sólo para comunicación epistolar. Era gratuita como también para la correspondencia que ellos recibieran. En principio, se imprimieron cinco modelos, pero luego aparecieron otras impresas por partidos, milicias, el SRI... U otras como la "Tarjeta de Miliciano", la "Tarjeta Postal de los A.U.S." (Amigos de la Unión Soviética) que editaba el Ministerio de Propaganda y la Junta Delegada de Defensa de Madrid o una "Tarjeta postal Infantil" para, sobre todo, los niños evacuados a Levante. $Y$ en la España franquista, Aracil afirma que también existieron pero que no ha hallado ninguna disposición que las autorizara. ${ }^{30}$

Y existía la posibilidad de que, "por no haber sellos en el estanco", el remitente acudiera al Consejo Municipal donde, en cumplimiento de la Ley $^{31}$, se le estampaba un sello para autorizar a la circulación de esa carta.

Cuando los franquistas impusieron su victoria, aún perduró el recuerdo de la República en sus sellos durante un tiempo. Aunque hubo quienes, quizá para reafirmar su lealtad al nuevo régimen, pegaron el sello republicano boca abajo en los sobres. En cualquier caso, encima del sello de la España derrotada se estampaba un signo o símbolo propio de los nuevos tiempos o la efigie del mismo Franco.

Y no había pasado todavía un mes del final oficial de la Guerra Civil Española cuando una orden del Ministerio de Hacienda autorizaba la circulación de dos clases de sellos de correos que reproducían la efigie de Franco y en el fondo el escudo del nuevo estado. Uno con valor facial de 70 céntimos en un color azul intenso y otro de 40 céntimos en verde intenso ${ }^{32}$.

\section{EL LENGUAJE: FORMALISMO, PROPAGANDA Y NIVEL CULTURAL.}

El lenguaje de una carta pone de manifiesto diversas realidades. A formalismos clásicos se añadieron otros propios de las circunstancias de la guerra. Otras veces, el lenguaje se tiñó de propaganda o reflejó el nivel cultural del autor.

Y, a pesar de la deshumanización del contexto, persistieron formalismos habituales de la correspondencia ("Estimado Manolo", "Queridísima Madre"; "Apreciable e inolvidable Adelina") que se regulaban desde antiguo en manuales epistolares o tratados de correspondencia. Pero, además, ahora aparecerían otras, conforme la guerra avanzaba, como producto cultural propio de las circunstancias bélicas y/o ideológicas, con frases o expresiones propias de los tiempos. Es más, la guerra motivaría la

\footnotetext{
${ }^{29}$ Carta de Miguel Bedos a su novia Josefina Bes (18/07/1937). Archivo particular de Francisco Cabrera Castillo.

${ }^{30}$ Francisco ARACIL, La Guerra Civil... op. cit. (pp. 108 a 115)

${ }^{31}$ La orden del 15 de febrero de 1856 establecía que si se agotaban los sellos, la carta se presentaría al Alcalde o, en su ausencia, al Secretario que escribiría al dorso del sobre "No hay sellos" con la localidad y la fecha. Francisco ARACIL, La Guerra Civil... op. cit. (pp. 96 y 97).

${ }^{32}$ BOE (Núm. 118). De 28/04/1939; pág. 2284.
} 
aparición de manuales epistolares para soldados, en ambos bandos, para enseñarles específicamente cómo escribir cartas: los formulismos adecuados, cómo responder, la estructura y el lenguaje que debía presentar si el destinatario era novio, amigo, los padres.... Y, además, también eran útiles para enseñar a escribir a muchos. ${ }^{33}$

También ese formulismo evolucionó. Si Miguel, al principio, dirigía la carta a "Señorita Josefina",

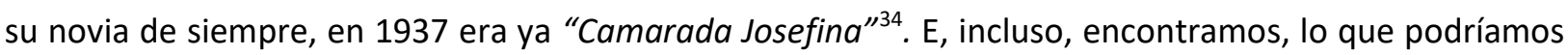
llamar un metalenguaje. Hay cartas con restos de barro porque... "Mientras escribo estas líneas me he visto obligado a hacer un 'cuerpo a tierra' lo que justifica que la carta esté manchada..." o, incluso, tinta corrida, producto de lo que, sinceramente, parecen ser lágrimas de un joven que escribía a su madre.

Esa adecuación del lenguaje a las circunstancias bélicas permite diferenciar, lógicamente, el bando al que se adscribe el remitente. Entre los franquistas, abundan expresiones como "rojos" o "rogelios", y, en el republicano, "fascistas" o, entre los peneuvistas, expresiones en vascuence propias del credo nacionalista ${ }^{35}$.

Esto se relaciona con el papel del correo en el esfuerzo de propaganda. Durante el conflicto, con los sobres y con las hojas distribuidas para escribir las cartas, viajaron encabezamientos con imágenes y breves textos de reafirmación ideológica o de propaganda. Aunque en ocasiones los autores de la carta escribieron de su puño y letra estos mensajes propagandísticos, cada vez fue más frecuente que, en el papel o incluso en el sobre, figuraran impresas frases o la efigie del "Caudillo" (o incluso este de cuerpo entero). Fueron invocaciones como "Saludo a Franco. Arriba España" o, simplemente, "Franco, Franco, Franco" $u$ otras que nos hablan de sensibilidad cercana al carlismo, como "iViva España! iViva Cristo Rey! iViva el Rey!”, “Dios-España-Franco” o, simplemente "D. P. R.” (o sea, “Dios Patria Rey”). También la significación franquista se observa en la forma de poner la fecha, con la referencia a "I (II o III) Año Triunfal". ${ }^{36}$ Seguro que hubo casos en que al remitente no le gustarían esas frases de adhesión, pero su uso era muchas veces o una imposición o la única posibilidad de contar con papel, con lo cual la propaganda era inevitable.

En la España republicana, en cambio, los encabezamientos no fueron ni tan ceremoniosos ni tan barrocos. Bastaban salutaciones como "Camarada", "Compañero" o "Estimados Compañeros. Salud" o "Camaradas antifascistas". Y, sólo en ocasiones, los combatientes usaron un papel con membrete de la unidad $u$ hojas con la figura de un miliciano en actitud vigilante. $Y$, a veces, los remitentes incluyeron símbolos tales como estrellas comunistas o una hoz y un martillo.

Pero también ideológicamente relevantes fueron las despedidas de las cartas de aquellos que se sentían más identificados con la causa. En el bando franquista hasta madrinas de guerra se despidieron

\footnotetext{
${ }^{33}$ Verónica SIERRA BLAS, Aprender a escribir cartas. Los manuales epistolares en la España contemporánea. Gijón; TREA; 2003 (pp. 73 a 79; 170, y 174 y 175).

${ }^{34}$ Colección de cartas de Miguel Bedos a su novia Josefina Bes. Archivo particular de Francisco Cabrera Castillo.

${ }^{35}$ Conjunto de cartas de Pedro María Ortiz. Fondos Incorporados; caja 1; Carpeta "L-414.196: Correspondencia a Manuel Valenzuela Peralta." CDMH-SALAMANCA. Y Archivo Histórico del Nacionalismo Vasco-Fundación Sabino Arana.

${ }^{36}$ Esto, además, formaba parte de las fórmulas propuestas en los manuales para los soldados franquistas como recoge SIERRA BLAS, Verónica. Aprender a escribir... op. cit., pp. 174 y 175.
} 
con un "iArriba España!" o "iViva nuestro Caudillo Franco!" y expresiones similares en letra, generalmente, más grande.

En la España republicana hallamos más romanticismo revolucionario: despedidas como "Vuestro y de la causa del pueblo", "Vuestro y de la causa antifascista", "Queda de vosotros y de la causa" o esta con la que un joven combatiente se mostraba plenamente identificado con la causa: "Saluda anárquicamente [el nombre]. Salud y anarquía. iViva la F. I. J. L" (o sea, la Federación Ibérica de Juventudes Libertarias). En los casos del mundo nacionalista vasco, el colofón más frecuente fue "saludo (o se despide) en JEL" (es decir, Jaungoikoa Eta Legizarra = "Dios y Ley vieja", clásica despedida peneuvista referido a un lema formulado por Sabino Arana) ${ }^{37}$.

Otro aspecto relevante del lenguaje de las cartas de la Guerra Civil es que fueron, en general, el reflejo de una competencia alfabética y gráfica escasa de muchos españoles, que no pudieron acudir a la escuela en el primer tercio del siglo XX, especialmente en el medio rural, el mayoritario en aquella España. Esta realidad se manifestó en que muchos escribían como hablaban, con los defectos y modismos del habla local. Eran cartas con carencias gramaticales, frases muy mal construidas, ignorancia absoluta de la ortografía. Además, presentaban mala caligrafía que obliga hoy al investigador a enormes esfuerzos, a veces incluso echar mano de lupas para identificar a qué letra se corresponde el garabato que hay sobre el papel. El lenguaje más que sencillo era rudimentario. En la correspondencia de guerra se plasmaron claramente las diferencias sociales y culturales que separaban al oficial del soldado. No obstante, en la trinchera se intentó paliar esas carencias culturales en la tropa con lo que la profesora Sierra denomina "delegados de escritura" para escribirles o leerles las cartas a los que eran incapaces de hacer ambas cosas. ${ }^{38}$

Otro dato que revela el análisis en las cartas es que el nivel cultural, siempre en términos generales, era superior en la España franquista. Aunque también habríamos de matizar mucho. De hecho, en el bando republicano encontramos más iniciativas para solucionar ese problema. Por un lado, las muy conocidas milicias de la cultura. O propuestas como la Cartilla del combatiente del SRI que conminaba a los que supieran leer y escribir a que enseñaran a los analfabetos, a los que motivaba la posibilidad de poder leer y escribir para comunicarse con sus familiares, amigos o parejas sin tener que recurrir a otros compañeros ${ }^{39}$.

No obstante, aunque lo anterior sea cierto, también lo es que entre los combatientes anarquistas, muchos de ellos también procedentes del mundo rural, los hubo que manejaban muy bien el castellano e, incluso algunos pedían que les proporcionaran libros para organizar una biblioteca ${ }^{40}$. 0 podemos referirnos igualmente a los nacionalistas vascos cuyo manejo del castellano estaba en niveles muy superiores al de la media.

\footnotetext{
${ }^{37}$ Varias cartas: Microfilmes 253 y 254; Archivo de la Fundación de Estudios Libertarios Anselmo Lorenzo (CNT), y en Archivo Histórico del Nacionalismo Vasco-Fundación Sabino Arana.

${ }^{38}$ SIERRA BLAS, Verónica. Aprender a escribir... op. cit., p. 76. Y en Juan Luis CALBARRO, "Un epistolario de guerra en el Archivo de la Escritura Popular Bajo Duero: La Correspondencia del teniente Agustín Morales con la familia del soldado José Montalvo (1937-1943)" en Antonio CASTILLO GÓMEZ (Ed.), Cultura escrita y clases subalternas: una mirada española. Oiartzun; SENDOA; 2001, pp. 173 a 182.

${ }^{39}$ SIERRA BLAS, Verónica. Aprender a escribir... op. cit., p. 76.

${ }^{40}$ Varias cartas: Microfilmes 253 y 254. Archivo de la Fundación de Estudios Libertarios Anselmo Lorenzo (CNT).
} 


\section{UN EPISTOLARIO MUY VARIADO.}

Los contenidos de las cartas de la Guerra Civil fueron muy variados, pero también responden muchos a los tópicos de la correspondencia bélica. Cartas de amor entre novios, cuyos afanes, ilusiones, proyectos de vida juntos se ven truncados de repente. Pero la guerra no consiguió hacer morir la relación... gracias a las cartas. Eso sí, durante casi tres años, pasó a ser un noviazgo epistolar... Y esas cartas expresan intensos deseos de estar juntos o con miedos ante la posibilidad de que eso nunca fuera posible ${ }^{41}$.

Lógicamente, abundaron las cartas dirigidas a la familia. La añoranza de los seres queridos se llenaba con recuerdos. Muy emotivas fueron, sin duda, las que un combatiente en el frente dirigía a sus hijos o al revés. Una pequeña escribió a su "querido papaíto mío", un comandante de la Legión. "Cenando un día que mamá estaba malita lloré mucho porque eres un papá muy querido pero nunca estás con nosotros"42.

Más frecuentes fueron las cartas de los combatientes que escribían a las madres, más que a los padres. En sus textos casi siempre todo iba bien, él no corría peligro y se encontraba estupendamente. "Yo estoy destacado en un caserío en el que hay abundancia de huevos y leche, y duermo con sábanas y todo" o "Ios rojos ya ni siquiera atacan y esto no parece una guerra." Eran los lógicos intentos de tranquilizar, que probablemente no lo conseguían. Además, palabras llenas de ternura, de consuelo, de alivio: "Queridísima madre: te mando con ésta el diario abrazo que te prometí siempre que pudiera" ${ }^{43}$.

La guerra separó familias y, a veces, la carta fue el medio, si no del anuncio de la muerte del ser querido, sí el relato de cómo ocurrió. Hipólito, soldado republicano, contó a los suyos la muerte de su hermano y cómo la confirmó: "Quiero haceros gracia de lo que vi. No puedo precisar exactamente mis impresiones de aquel momento (...) Allí estaba Aniceto, el pobre Aniceto, que si bien debió sufrir dolores atroces en sus últimos momentos..." ${ }^{\prime 44}$ Había sido víctima de un bombardeo.

También la guerra separó grupos de amigos. Frecuentemente lucharon en frentes distintos, pero ya no podían tertuliar cara a cara y lo hacían a través del papel. Los temas eran los mismos... más la guerra. Además, la carta tranquilizaba: recibirla era constatar que el amigo seguía con vida.

En este tipo de cartas, el tono era habitualmente desenfadado, con chascarrillos y bromas. Jaime escribió a Manuel: "Pajolero Manolo: Veo por tu carta del día 27 (...) que se ha multiplicado tu considerable cantidad de 'guasa' que siempre has albergado en ese cuerpo serrano, honra y prez de Bidebarrieta-Street y medalla de plata del club deportivo. iPorque los adjetivos 'robusto y fuertote' con que encabezabas traían peores intenciones que un miura 'pregonao'! (...) Decididamente los hay con potra y entre ellos estas tú."

Y los contenidos que dos veinteañeros charlarían en un encuentro habitual... "Ahora, sin guasa, te diré. (...) Al demonio se le ocurre mentar a Carmen ... en la carta, que cuando llegó a casa fue abierta

\footnotetext{
${ }^{41}$ Varias cartas de Miguel Bedos a su novia Josefina Bes. Archivo particular de Francisco Cabrera Castillo,

${ }^{42}$ Carta de Marinés, hija del Comandante en jefe de la XIII Bandera de la Legión a su padre (27/08/1938). Colección privada de la familia de Ana Merino Sobrini.

${ }^{43}$ Cartas de Borja de Arteaga y Falguera a su madre, en C. ARTEAGA Y FALGUERA, Borja. Madrid, 1941.

${ }^{44}$ Carta de Hipólito Echepare Marticorena a su familia (22/05/1937). Archivo particular de Javier Echeverría Echepare.
}

HISPANIA NOVA., 15 (2017), págs. 125-146 DOI: https://doi.org/10.20318/hn.2017.3483 
violentamente por mi... hermanita. Aparte de todo son figuraciones tuyas. Sigo impermeable al bello sexo y ni siquiera tengo madrina. Desde que fracasé con tu recomendada, me corté la coleta” ${ }^{45}$.

Además, la Guerra truncó la vida cotidiana en terrenos muy peculiares, pero importantes para muchos. Aunque hubo capellanes en el ejército franquista o entre los nacionalistas vascos, hubo soldados que optaron por mantener una correspondencia con aquél que antes de julio de 1936 había sido su confesor o director espiritual. Por otro lado, en la clandestinidad de la religión en la España republicana hubo sacerdotes, ocultos, que intentaron, en lo posible, seguir atendiendo a sus feligreses y recibieron, lógicamente en mano y no por correo, cartas de cristianos que reclamaron su dirección espiritual. Y, de la misma forma, fueron aconsejados en respuesta por escrito. ${ }^{46}$

$\mathrm{Y}$, además, aflora otro contenido habitual en la correspondencia bélica: la religiosidad. Se reza por la pareja, por el hijo, por el amigo, por el ahijado... que está en el frente, o lo hace el combatiente para que Dios proteja a sus seres queridos en la retaguardia. Conchita, cuya carta trasluce que pretendía un noviazgo con Manuel, vivía en Zaragoza y le dijo que "tiene mucha devoción a la Virgen del Pilar" e iba a rezar por él ${ }^{47}$. También María y Arturo, padres de este mismo Manuel, a la vez que trataban de animarlo, le aseguraban que rezaban por él ${ }^{48}$. Y en el lado republicano, Miguel le contó a su novia que, cuando buscaban caracoles, se encontraron una imagen de la Virgen que él identifica como de una ermita cercana y que fueron muchos a verla y aunque no lo dice expresamente, sí parece insinuar que para pedirle protección. Porque en Miguel afloró la devoción a la Virgen “...de noche veo las luces de Zaragoza y de día hasta veo la Pilarica" 49 . Más claro es el componente religioso del nacionalismo vasco que también apareció en el miedo de una madre que le expresó a su hijo, un gudari, "la confianza en protección de la Virgen" a la que ella lo encomendaba ${ }^{50}$. O conforme la guerra avanzaba, asomaban también en las cartas las oraciones para pedir que concluyera porque ya se estaba muy harto y cansado, incluso en la España franquista ${ }^{51}$.

Y como derivación lógica de un contexto de guerra hallamos en las cartas una frecuente presencia de alusiones a la muerte. En este ámbito, apenas encontramos diferencias entre las dos Españas, en el lenguaje, los conceptos, los sentimientos, las ideas o las creencias religiosas.

\footnotetext{
45 Carta de Jaime de Olaso y Olaso a Manuel Valenzuela Peralta (22/11/1938). Fondos Incorporados; caja 1; Carpeta "L-414.196: Correspondencia a Manuel Valenzuela Peralta." CDMH-SALAMANCA.

${ }^{46}$ Hallamos muchos testimonios de esto en la documentación que se conserva en el Archivo de España de la Compañía de Jesús localizado en Alcalá de Henares.

${ }^{47}$ Carta de Conchita Cuartero Ortiz a Manuel Valenzuela (28/12/36). Fondos Incorporados; caja 1; Carpeta "L414.196: Correspondencia a Manuel Valenzuela Peralta." CDMH-SALAMANCA.

${ }^{48}$ Carta de María y Arturo a su hijo Manuel Valenzuela (10/05/37). Fondos Incorporados; caja 1; Carpeta "L414.196: Correspondencia a Manuel Valenzuela Peralta." CDMH-SALAMANCA.

49 Dos cartas de Miguel Bedos a su novia Josefina Bes (14/06/37 y 24/09/37). Archivo particular de Francisco Cabrera Castillo.

${ }^{50}$ Carta de una madre de un gudari a Telesforo Monzón (21/05/37). GE 182-24. Archivo Histórico del Nacionalismo Vasco-Fundación Sabino Arana

${ }^{51}$ Varias cartas dirigidas a Manuel Valenzuela de familia, amigos y madrinas de guerra escritas en la segunda mitad de 1938. Fondos Incorporados; caja 1; Carpeta "L-414.196: Correspondencia a Manuel Valenzuela Peralta." CDMHSALAMANCA.
}

HISPANIA NOVA., 15 (2017), págs. 125-146 DOI: https://doi.org/10.20318/hn.2017.3483 
La mayoría de las veces se colaba la muerte en cartas de despedida: "Querida madre: me voy al otro mundo con el alma transida por el dolor por no poderte dar el último abrazo, pero qué vamos a hacer. iPaciencia! Ya llegó la hora, me matan sin yo haber hecho delito ninguno (...) Mis últimos pensamientos serán para usted y para mi hermana (...) Adiós madre y hermana para siempre, hasta la eternidad. Mi abrazo y muchos besos para las dos, los últimos. Adiós para siempre ${ }^{\prime 52}$.

Estas cartas, son las "escrituras últimas", en expresión de Petrucci ${ }^{53}$ que afirma que presentan una historia de vivos y de vida (de ahí que se use la expresión "hasta la eternidad" por el convencimiento de que se volverían a encontrar). Las destinatarias solían ser la madre o la esposa y constituyen los testimonios más valiosos para conocer los pensamientos, los deseos y los sentimientos más íntimos de sus autores. Presentan una uniformidad estructural y una homogeneidad textual: los sentimientos y pensamientos son similares en todos, y la escritura tiene mucho de ritual: suelen contar todas lo mismo y hasta de la misma manera ${ }^{54}$. Por ello, Fabio Caffarena las define como una "autobiografía en miniatura" ${ }^{55}$. Y como muchos condenados temían que los cauces oficiales alteraran el contenido de las cartas o simplemente estas no llegaran a su destino, prefirieron utilizar medios clandestinos: las escondían en algún objeto o las enviaban mediante enlaces como compañeros presos, vigilantes o funcionarios más o menos afines o más humanitarios ${ }^{56}$.

Otras veces no fueron cartas "en capilla", sino textos de un combatiente que pensaba en la posibilidad de morir en un próximo enfrentamiento: "Quisiera escribirte una larguísima carta -escribe Borja desde Peña Lemona a su madre- pero no puedo ni me siento capaz de hacerlo. Esta carta es una despedida, pues creo que esta tarde Dios me llamará." Al día siguiente un disparo acabaría con la vida de Borja ${ }^{57}$.

Pero la muerte también asomó en las cartas en su forma más repugnante: la de los que se congratularon de realizar una ejecución... "Mi llegada a este Madrid ha sido triunfal, pues el caso es que Ilegué al cuartel y estaba el calabozo lleno de facciosos y se sorteaban para ir a pasearlos y salimos 10 por voluntad y nos los llevamos por allí por las Delicias y les dimos el 'paseíto' a 11, y allí había un chico que estaba borracho y por poco nos lo cargamos a él también porque se sacó una pistola..." ${ }^{58}$. Estamos ante las cartas más deshumanizadas de la guerra, pero que también fueron producto de esta tragedia.

\footnotetext{
52 Carta de José María de Amadoz Aguinaga a su madre y hermana (15 y 16/12/1937). GE: 406-1. Archivo Histórico del Nacionalismo Vasco-Fundación Sabino Arana.

53 Armando PETRUCCI, Escrituras últimas. Ideología de la muerte y estrategias de los escritos en el mundo occidental. Buenos Aires, Ampersand, 1995. Citado por Verónica SIERRA BLAS, Cartas presas. La correspondencia carcelaria en la Guerra Civil y el Franquismo. Madrid, Marcial Pons; 2016, p. 215.

${ }^{54}$ Verónica SIERRA BLAS, La correspondencia carcelaria... op. cit., pp. 231 a 253.

${ }^{55}$ Fabio CAFFARENA, Lettere dalla Grande Guerra. Scritture del quotidiano, monumento della memoria, fonti per la storia. Il caso italiano. Milán; Unicopli; 2005. Citado por SIERRA BLAS Verónica. La correspondencia carcelaria... op. cit., p. 253.

${ }^{56}$ Verónica SIERRA BLAS, La correspondencia carcelaria... op. cit., p. 227.

${ }^{57}$ Cartas de Borja de Arteaga y Falguera; publicadas en ARTEAGA Y FALGUERA, C. Borja.

${ }^{58}$ Carta de Francisco Marza a un amigo (22/08/1936). Archivo particular de Clemente González.
} 
También las cartas recogieron amores o afectos surgidos en la guerra. Muchos se concretaron en las madrinas de guerra" ${ }^{59}$. Apreciable señorita (...) Las guerras traen consigo modalidades que es preciso acatar por su clasicismo. Una de ellas es la de que todo soldado no se considera tal (...) sin tener a quien dedicar sus actos y sus pensamientos" ${ }^{\prime \prime 0}$. Si ella aceptaba, se produciría un carteo entre amistad y flirteo, siempre en un tono de respeto. Ella, la madrina, mantendría la esperanza en que regresara de la trinchera, para poder conocer al soldado personalmente. Al combatiente esas cartas le animaban porque contaba con alguien en la retaguardia que pensaba en él.

Oficialmente las madrinas sólo actuaron en la España franquista. Pero entre las filas republicanas también encontramos fórmulas parecidas. En organizaciones como la Solidaridad Internacional Antifascista, unas mujeres en una oficina en Barcelona, se encargaron de atender a quienes, desde el frente, acudían a ellas: "Camaradas de la S.I.A. iSalud! Después de muchos días de no haberos escrito la carta que, en mi última tarjeta postal os prometí, cojo hoy la pluma..." Porque... "me siento solo y aburrido y envidio la suerte de los otros que reciben, y esperan, correspondencia con interés indescriptible. Yo nunca he recibido ni una sola carta ni paquete... A ver si entre vosotras existe una que quiera aliviar mi existencia y llevarle un poco de aliento... Siempre rehuí la idea de buscarme una madrina (...), pero ahora me acojo a ello como el náufrago al bote de salvamento." Pero una "madrina" era poco "revolucionario" o, quizá, había que marcar las distancias con la otra España y las mujeres del SIA respondieron que aunque "estás muy solo, no podemos proporcionarte ninguna madrina de guerra pero puedes seguir escribiendo a esta Sección del Combatiente que te acogerá con el calor y cariño que todo combatiente que está en una trinchera defendiendo nuestra Libertad querida merece."

Además, hay un conjunto de contenidos que son recurrentes y habituales en la correspondencia bélica: la comida, el miedo, el ocio o tiempo libre...

A los pocos meses de iniciado el conflicto, la comida empezó a escasear en algunas zonas, más en un bando que en otro y tanto en la retaguardia como en el frente. En general, en el bando franquista se comió mejor, especialmente en el área rural. Así lo expresa Margarita desde Medina del Campo que, en mayo de 1937, le cuenta a su sobrino Luis Rodríguez que está en Talavera y hasta que "hacemos algo de queso" y que "si necesitáis algo lo pedís para mandarlo." ${ }^{61}$

En cambio, en muchas zonas de la España republicana la alimentación no fue tan fácil. Se pasó más hambre, especialmente en las ciudades. En Madrid, Magdalena Ocaña, en junio de 1937, escribió que ante la escasez de comida "matan a los perros". ${ }^{62}$ Hubo momentos en el frente, sobre todo si era en zonas rurales, en que "hicimos una cena muy buena", le cuenta Miguel a su novia, en noviembre de $1937^{63}$. Por otra parte, el combatiente republicano que contaba con una buena paga se podía permitir que "el domingo compramos un cordero." ${ }^{64}$ Sin embargo, su Josefina escribía sobre las penurias que

\footnotetext{
${ }^{59}$ Véase Manuel DE RAMÓN y Carmen ORTIZ. Madrina de guerra: Cartas desde el frente. Madrid, La Esfera de los libros, 2003.

${ }^{60}$ Carta de Serafín Marrón a su novia Adelina Menéndez (12/10/1938). Archivo particular de Adelina Menéndez.

${ }^{61}$ Carta de Margarita a Luis Rodríguez Revilla (17/05/1937). Archivo particular de Javier Sáenz del Castillo.

${ }^{62}$ Carta de Magdalena Ocaña a Luis Rodríguez Revilla (29/05/1937). Archivo particular Javier Sáenz del Castillo.

${ }^{63}$ Carta de Miguel Bedos a su novia Josefina Bes (28/11/1937). Archivo particular de Francisco Cabrera Castillo.

${ }^{64}$ Carta de Miguel Bedos a su novia Josefina Bes (9/02/1938). Archivo particular de Francisco Cabrera Castillo.
} 
estaba pasando. En febrero de 1937 escribió: “...tienen que hacer mucha cola para el pan porque escasea", o dos meses que "no hay comida" en su pueblo, Batea (Tarragona) ${ }^{65}$.

Pero la situación no era igual en toda la zona republicana, pues José Nogué, en Tarragona capital, contó que tenían comida y debía de ser abundante porque esa circunstancia les servía por ejemplo para cambiarla por tabaco ${ }^{66}$. Este comenzó a escasear en enero de 1938 y José se lamentó de que, aunque disponen de comida (en marzo afirma que "nos hemos dado un banquete en la playa"), lo que no podían era cambiarla por ese tabaco. ${ }^{67}$

No obstante, el desarrollo negativo de la guerra hizo aparecer también en Tarragona la escasez en junio de 1938 ("la comida ya no hay tanta, escasea") hasta el punto de que el día 11 escribió: "...voy a ver si mango unas patatas de las que mañana van a hechar (sic) en el potaje, para después ver de freirlas (sic). No sé si podré pero voy a intentarlo." Tres días después en otra carta, confirmaba que logró su objetivo y otros escritos posteriores mostraron que no fue la última vez. Además, ese verano del 38 aparecieron en sus cartas referencias a que la gente se comía animales muertos por los bombardeos. O fue, de nuevo, la buena paga del combatiente lo que permitió a José comprar comida en las masías, eludiendo las colas del racionamiento ${ }^{68}$, como a otro combatiente, el anarquista Vicente Capdevila, contar a un amigo cómo se movía por zonas de La Mancha para obtener víveres. ${ }^{69}$ Las referencias a las dificultades para comer se incrementaron a lo largo de 1938 en la zona republicana, pero estas alusiones no las encontramos en cartas escritas desde el otro bando.

A veces la comida, en quienes podían permitírselo, fue parte del disfrute del tiempo libre del combatiente como también lo fue el fútbol, el baile, el cine...

Muchas veces relatar a los seres queridos cómo el combatiente aprovechaba su ocio era una forma más de tranquilizarlos porque mostraba que, al menos, no lo pasaba tan mal como podría sugerir pensar en una trinchera. Miguel, cuando estuvo en el frente estabilizado de Aragón, refirió, repetidas veces, que había ido al cine ("ponen unas películas muy bonitas" ${ }^{70}$ ), o que, en Sariñena y con un permiso "fuimos a ver 'El Conde de Montecristo' y jugamos al fútbol..." ${ }^{71} \mathrm{O}$, por ejemplo, José Nogué en una carta del 21 de junio de 1938 contó que aparte de disfrutar de la playa, del cine o del baile, asistió a

\footnotetext{
65 Dos cartas de Josefina Bes a su novio Miguel Bedos (23/02 y 18/04/1937). Archivo particular de Francisco Cabrera Castillo.

${ }^{66}$ Carta de José Nogué a su familia (25/12/1937). Fondos Incorporados; caja 2; Carpeta "Correspondencia del soldado José Nogué Vallejo con su familia durante la Guerra Civil (1936-1939)". CDMH-SALAMANCA.

${ }^{67}$ Diversas cartas de José Nogué a su familia entre enero y marzo de 1938. Fondos Incorporados; caja 2; Carpeta "Correspondencia del soldado José Nogué Vallejo con su familia durante la Guerra Civil (1936-1939)". CDMHSALAMANCA.

${ }^{68}$ Diversas cartas de José Nogué a su familia en la segunda mitad de 1938. Fondos Incorporados; caja 2; Carpeta "Correspondencia del soldado José Nogué Vallejo con su familia durante la Guerra Civil (1936-1939)". CDMHSALAMANCA.

${ }^{69}$ Carta de Vicente Capdevila a su amigo Antonio (27/10/1936). Archivo particular de Clemente González.

${ }^{70}$ Carta de Miguel Bedos a su novia Josefina Bes (14/06/1937). Archivo particular de Francisco Cabrera Castillo.

${ }^{71}$ Carta de Miguel Bedos a su novia Josefina Bes (26/07/1937). Archivo particular de Francisco Cabrera Castillo.
} 
un partido de fútbol que se organizó en el frente del Ebro ${ }^{72}$ y en otras cartas hizo repetidas referencias, en especial a partir del verano de 1938, a partidos de fútbol los domingos en los que él participaba. $Y$ en el otro bando también: el alférez Pedro María Ortiz le contó a su amigo Manuel Valenzuela, a finales de 1938, cómo se distraía jugando varios partidos de fútbol en las cercanías de Monzón (Huesca) donde estaba con su unidad. ${ }^{73}$ Otra opción para combatientes republicanos tan bien pagados como Miguel Bedos era pasar de permiso "una tarde de tabernas y cafés", en este caso en Cuenca. ${ }^{74}$

También las novias o madrinas contaron en sus cartas como se distraían o se divertían. Josefina escribió que en su pueblo, de vez en cuando acudía a bailar con sus amigas. ${ }^{75}$ Una madrina, Emilia de Jerez de la Frontera, le contó algo similar a su ahijado Manuel ${ }^{76}$.

Ese tiempo libre contribuyó a distraer el pensamiento del constante riesgo en que se vivía en situación de guerra. El miedo fue otra de las referencias habituales en las cartas. Y este temor se concentró en dos ámbitos: el frente o la trinchera, por los combates, y en la retaguardia, por los bombardeos. Y las cartas lo que plasmaron fue el miedo de quien padecía la situación de riesgo o del que era consciente del riesgo que corría el ser querido con el que se carteaba. Josefina manifestó a Miguel su miedo por los combates y él le tranquilizó asegurándole "que me han alejado de la primera línea" ${ }^{77}$. También las madrinas escriben a sus ahijados para que se cuiden y para que "Dios quiera que salgáis bien..." ${ }^{78}$ Otras ocasiones el miedo nació de rumores, bulos o lo que se contaba. Así Josefina advertía a Miguel que debía... "tener cuidado con los moros que son muy criminales"79.

Y en la retaguardia el miedo procedió de los bombardeos, cuyas alusiones no faltaron en las cartas. Por un lado, el combatiente pedía a los suyos que tuvieran cuidado y que se protegieran como él lo hacía en la trinchera ${ }^{80}$. Otros combatieron el miedo a las bombas con la sorna: José escribió a su familia en Madrid que "...la vida [está] pendiente de una palanca que se conecta con el cargamento de bombas de un trimotor" pasando "a ratos tranquilidad, a ratos alarma" ${ }^{81}$. 0 en julio de 1938 informó a

${ }^{72}$ Carta de José Nogué a su familia (21/06/1938). Fondos Incorporados; caja 2; Carpeta "Correspondencia del soldado José Nogué Vallejo con su familia durante la Guerra Civil (1936-1939)". CDMH-SALAMANCA.

${ }^{73}$ Carta de Pedro María Ortiz a Manuel Valenzuela (16/12/38). Fondos Incorporados; caja 1; Carpeta "L-414.196: Correspondencia a Manuel Valenzuela Peralta." CDMH-SALAMANCA.

${ }^{74}$ Carta de Miguel Bedos a su novia Josefina Bes (9/02/1938). Archivo particular de Francisco Cabrera Castillo.

75 Diversas cartas de Josefina Bes a Miguel Bedos (varias fechas de 1936 y 1937). Archivo particular de Francisco Cabrera Castillo.

${ }^{76}$ Carta de Emilia a Manuel Valenzuela (10/05/1938). Fondos Incorporados; caja 1; Carpeta "L-414.196: Correspondencia a Manuel Valenzuela Peralta." CDMH-SALAMANCA.

77 Carta de Josefina Bes a Miguel Bedos (25/06/1937) y de Miguel a Josefina (4/09/37). Archivo particular de Francisco Cabrera Castillo.

${ }^{78}$ Carta de Pilar Ponce de León a Manuel Valenzuela Peralta (11/01/1939). Fondos Incorporados; caja 1; Carpeta "L-414.196: Correspondencia a Manuel Valenzuela Peralta." CDMH-SALAMANCA.

${ }^{79}$ Carta de Josefina Bes a Miguel Bedos (12/09/1937). Archivo particular de Francisco Cabrera Castillo.

${ }^{80}$ Carta de José Nogué a su familia (8/01/1938). Fondos Incorporados; caja 2; Carpeta "Correspondencia del soldado José Nogué Vallejo con su familia durante la Guerra Civil (1936-1939)". CDMH-SALAMANCA.

81 Dos cartas de José Nogué a su familia (25/03 y 30/03/1938). Fondos Incorporados; caja 2; Carpeta "Correspondencia del soldado José Nogué Vallejo con su familia durante la Guerra Civil (1936-1939)". CDMHSALAMANCA.

HISPANIA NOVA., 15 (2017), págs. 125-146 DOI: https://doi.org/10.20318/hn.2017.3483 
los suyos de que, tras un bombardeo, "se dan comilona por si no tienen otra oportunidad" 82 . Este combatiente, en Tarragona, terminó por manifestar, desde el verano de 1938, "que está harto de las continuas incursiones de aviones y ya ha perdido el miedo y muchas veces ni acude a los refugios". Esto no evitaba que su familia en Madrid le expresara su temor ante ese proceder poco prudente ${ }^{83}$. $Y$ es que era habitual que las cartas de retaguardia expresaran "terror" ante los bombardeos en la ciudad ${ }^{84}$.

Y en la España republicana, especialmente desde 1938, asomó el derrotismo en las cartas. Anhelaban el final de la Guerra sí o sí, independientemente de quien venciera. Los combatientes querían volver a casa.

Un soldado confesó que aunque él detestaba el fascismo "porque apestaba del militarismo", odiaba la guerra aún más. Milicianos de la primera hora, admitieron su desilusión y sólo deseaban que la guerra terminara inmediatamente. La posición bien conocida de Manuel Azaña, Presidente de la República, encontró más adeptos entre las tropas que la política de resistencia desesperada de Juan Negrín, el Jefe del Gobierno. Uno opinaba que aquellos que, como Negrín, hablaban de "resistir" nunca habían tenido hambre. Otro, de Murcia, creía que el voluntariado para luchar fue la acción más estúpida posible. Un "profeta" desconocido hizo la predicción, casi cierta, de que la Guerra habría terminado en marzo de 1939. El derrotismo general o indiferencia ante el destino de la República impregnaban las cartas de los soldados republicanos ${ }^{85}$.

Y es a partir de este momento, 1938, cuando se observó como el lenguaje se hizo más agrio y quejoso de la situación. Aparecía el "Nosotros" de los soldados de bajo rango, frente a "ellos", alusivo a los oficiales; transmitía el resentimiento de los primeros. Los enfermos, los exentos, y casi cualquier persona que lograra evitar la primera línea despertaban la envidia entre los soldados en el frente. Los censores informaron de que, después de los alimentos, los privilegiados que evitaban las trincheras generaban el mayor número de quejas. Uno que fue movilizado revelaba que sus colegas estaban calientes y bien alimentados y llegó a la conclusión de que la guerra afectó, por encima de todo, a los "trabajadores pobres que [eran] los únicos que morían en el campo de batalla." Cartas con estos contenidos invadieron la vanguardia y la retaguardia lo largo de 1938 y 1939, y algunos de los descontentos escribían sobre los desertores. El problema de las deserciones llegó a tal gravedad que, para evitarlas, las autoridades republicanas hicieron circular cartas que informaban que los franquistas habían confiscado los bienes de las familias de los "rojos". Sin embargo, las deserciones no dejaron de aumentar en los últimos meses de la Guerra ${ }^{86}$.

\footnotetext{
${ }^{82}$ Carta de José Nogué a su familia (28/07/1938). Fondos Incorporados; caja 2; Carpeta "Correspondencia del soldado José Nogué Vallejo con su familia durante la Guerra Civil (1936-1939)". CDMH-SALAMANCA.

${ }^{83}$ Diversas cartas de José Nogué a su familia (desde mediados de agosto de 1938). Fondos Incorporados; caja 2; Carpeta "Correspondencia del soldado José Nogué Vallejo con su familia durante la Guerra Civil (1936-1939)". CDMH-SALAMANCA.

${ }^{84}$ Carta de Conchita Cuartero Ortiz a Manuel Valenzuela (28/12/1936). Fondos Incorporados; caja 1; Carpeta "L414.196: Correspondencia a Manuel Valenzuela Peralta." CDMH-SALAMANCA.

${ }^{85}$ Estas cartas están recogidas en Eduardo PONS PRADES, Un soldado de la República. Madrid; Gregorio del Toro, 1974, p.351 y en los fondos del Servicio Histórico Militar (Ávila) recogidos por SEIDMAN, Michael. "Quiet fronts..." op. cit.

${ }^{86}$ Cartas conservadas en los fondos del Servicio Histórico Militar (Ávila) recogidos por SEIDMAN, Michael. “Quiet fronts..." op. cit.
} 


\section{ONCLUSIÓN}

En suma, con mayores o menores dificultades en la expresión, los españoles de hace ocho décadas, a través de sus cartas nos han contado las historias mínimas, pero esenciales, de la gran tragedia española del siglo XX. En ellas no encontramos los grandes análisis militares y/o políticos del desarrollo de la Guerra. Pero conocemos la visión más humana y, en algunos casos, más cercana a la verdadera realidad vivida por los españoles de hace 80 años que pasaron aquella experiencia. Algunos dirán que se trata de una historia subjetiva de la Guerra Civil. No lo negamos, pero nunca la deberían rechazar porque es parte esencial de la Historia de este trágico episodio de la España contemporánea, y uno de los mejores caminos para comprenderlo.

Las cartas narran la experiencia de los que vivieron la Guerra Civil, cuando estos se la contaran a otros $y$, si estos respondieron, además, nos reportan los sentimientos, ideas, actitudes... que la recepción de esas cartas generó en ellos. Porque en este trabajo hemos comprobado que las cartas durante la Guerra Civil llegaron, con más o menos rapidez, a su destino. Por un lado, el correo más "ordinario" supo cómo adaptarse a las especiales circunstancias para continuar prestando un servicio lo más eficaz posible. Por otro lado, hubo necesidad de organizar mecanismos extraordinarios para mantener al máximo posible el contacto postal entre españoles separados. Y, de una u otra forma, el correo funcionó aceptablemente.

Es habitual que una guerra origine escasez, y también ello afectó al correo. Pero la escasez de material, papel y sellos sobre todo, suscitó soluciones imaginativas y, en cualquier caso, ello no impidió, aunque dificultara, la circulación de las cartas.

Y cómo contaban la guerra y sus circunstancias, el lenguaje de estas comunicaciones expresaba unas veces, la propia crueldad y deshumanización de la guerra; otras, la añoranza del ser querido o las escaseces de la situación. Pero también había cabida para el amor o para el disfrute del ocio; el miedo a la muerte y, muchas veces junto a ello, el pensamiento en Dios ante esa situación límite. Fue la vida en guerra. Todo ello se podía mezclar con una muestra de las carencias culturales y/o educativas de aquellos españoles. Además, podía manifestar el grado de compromiso ideológico con el bando en el que combatían o la parte de España en la que les había tocado pasar la Guerra.

En otras ocasiones, una carta fue un medio para llevar el consuelo o la esperanza y tranquilizar a quien sufría por saber que el hijo, el esposo, el hermano, el amigo... estaba en el arriesgado frente. Y en la Guerra Civil, además, se arbitraron medios para que esas cartas permitieran el contacto entre familias separadas repentinamente en julio de 1936, o a niños separados de su familia, para protegerlos de la tragedia, con sus padres.

Por otro lado, la censura es un elemento clásico de la correspondencia bélica. Pero no fue igual en ambos bandos. En el lado franquista, se censuraba políticamente y las referencias militares, pero además contenidos religiosos o morales. Aunque la hicieron muchos, acabó siendo misión de los capellanes en el ejército. $Y$ en la España republicana, el control censor fue menor y menos efectivo, como muestran las cartas en las que afloraban las críticas entre diversas facciones del lado republicano. Eso sí, ambos bandos elaboraron y aprobaron nuevas normas para el control de los contenidos postales durante la Guerra, pero la reiteración de las mismas, y hasta el contenido de estas, nos revela que la censura, en ambos bandos y por causas distintas, eso sí, no fue excesivamente rigurosa. 
En suma, estas "historias mínimas" de la Guerra Civil Española constituyen, como sabemos que otros estudios han demostrado para otros conflictos fuera de España, un elemento esencial para conocer y entender la vida cotidiana de los españoles que participaron y sufrieron la Guerra de España. 